\title{
O DIA QUE O AUDIOVISUAL INVADIU A AULA DE GEOGRAFIA E (DES)NORTEOU O CINEMA
}

\author{
THE DAY WHEN AUDIOVISUAL INVADED THE GEOGRAPHY CLASS AND \\ (DIS)ORIENTED THE CINEMA
}

\author{
EL DÍA QUE EL AUDIOVISUAL INVADIÓ LA CLASE DE GEOGRAFÍA Y \\ (DIS)GUIÓ EL CINE
}

Valéria Cazetta1 ; Ingrid Rodrigues Gonçalves ${ }^{2}$

\begin{abstract}
RESUMO
Nosso intuito, neste texto, é apresentar os resultados de um estudo realizado pela Rede internacional de pesquisas "Imagens, geografias e educação" acerca de como professoras/es de geografia relacionam cinema e práticas docentes. Valemo-nos de parte das respostas desse estudo para ponderar como materiais cinematográficos e audiovisuais são empregados nas ambiências escolares. Relacionamos tais ponderações com macrodiretrizes do setor audiovisual brasileiro e observações acerca do uso corriqueiro do audiovisual em nossas vidas na contemporaneidade. Nossa hipótese de trabalho é que o encontro entre geografia, cinema, audiovisual e educação acontece numa fronteira tênue, especialmente no contexto da sociedade educativa epicentro de um modo de vida alicerçado no aprendizado vitalício, que tem nos materiais audiovisuais uma de suas grafias fulcrais. Para esquadrinhar essa hipótese, articulamos quatro peças discursivas por meio de uma análise micropolítica e concluímos que, a partir do referido encontro, haveria algo de paradoxal em torno do que viria a ser o sentido e o não-sentido na educação geográfica. O sentido costuma ser entabulado, na esteira das pedagogias construtivistas, à axiomática de que, para aprender, é condição sine qua non despertar o interesse dos estudantes para algo ou alguma coisa. O não-sentido seria o oposto disso, ou seja, acontecimentos rotineiros que, ao atravessarem e modificarem as dinâmicas do tecido social, adentrariam as aulas de geografia, embaralhando as fronteiras entre o cinema e o audiovisual.
\end{abstract}

PALAVRAS-CHAVE: Educação. Cinema. Audiovisual. Ensino de geografia. Mudança social e educação

\footnotetext{
${ }^{1}$ Doutora em Geografia - Universidade Estadual Paulista Júlio de Mesquita Filho (UNESP). Rio Claro, SP. Professora da Escola de Artes, Ciências e Humanidades da Universidade de São Paulo (EACH-USP). São Paulo, SP - Brasil. E-mail: vcazetta@gmail.com

${ }^{2}$ Mestra em Educação - Universidade de São Paulo (USP). São Paulo, SP - Brasil. Professora - Centro de Estudos e Pesquisas de Administração Municipal (Etec CEPAM). São Paulo, SP - Brasil. E-mail: ingridgoncalves85@gmail.com
}

Submetido em: 04/10/2020 - Aceito em: 16/02/2021 


\section{ABSTRACT}

The purpose of this text is to discuss the results of a study organized by the International Research Network "Images, Geographies and Education" about how geography teachers combine cinema and teaching practices. We used part of the answers of this study to consider how cinematographic and audiovisual materials are used in schools. We relate these considerations to macro guidelines of the Brazilian audiovisual sector and to the everyday use of audiovisual in our lives today. Our hypothesis is that the encounter of geography, cinema, audiovisual and education takes place in a tenuous border, especially in the context of the learning society - the epicenter of a way of life based on lifelong learning, which has in audiovisual materiais one of its crucial writings. To explore this hypothesis, we articulated four discursive pieces through a micropolitical analysis. From that encounter, there would be something paradoxical about what could be the sense and the non-sense in geography education. The sense is usually related to constructivist pedagogies, to the axiomatic that in order to learn it is a sine qua non condition to motivate the interests of the students to something. The non-sense would be the opposite of that, when daily events produce changes in society, and then, would enter geography classes, blurring the boundaries between cinema and audiovisual.

KEYWORDS: Education. Cinema. Audiovisual. Geography education. Social change

\section{RESUMEN}

Nuestra intención, en este texto, es presentar los resultados de un estudio realizado por la Red Internacional de Investigación “Imágenes, geografías y Educación” sobre cómo los profesores de geografía relacionan el cine con las prácticas docentes. Utilizamos parte de las respuestas de este estudio para considerar cómo se utilizan los materiales cinematográficos y audiovisuales en las escuelas. Relacionamos estas consideraciones con amplias metas del sector audiovisual brasileño y observaciones sobre el uso cotidiano del audiovisual en nuestra vida actual. Nuestra hipótesis de trabajo es que el encuentro entre geografía, cine, audiovisual y educación ocurre en una tenue frontera, especialmente en el contexto de la sociedad educativa - epicentro de una forma de vida basada en el aprendizaje a lo largo de la vida, que tiene en los materiales audiovisuales una de sus grafías clave. Para explorar esta hipótesis articulamos cuatro piezas discursivas a través de un análisis micropolítico, y concluimos que, a partir de ese encuentro, habría algo paradójico en lo que sería el sentido y el sin sentido en la educación geográfica. El sentido acostumbra ser establecido, en la estera de las pedagogías constructivistas, al axiomática de que, para aprender, es condición sine qua non, despertar el interés de los estudiantes para algo o alguna cosa. El sin sentido sería lo opuesto a eso, es decir, acontecimientos diarios que, al atravesaren y cambiaren la dinámica del tejido social, entrarían en las clases de geografía, desdibujando las fronteras entre cine y audiovisual.

PALAVRAS-CLAVE: Educación. Cine. Audiovisual. Enseñanza de geografia. Movimiento social y educativo

\section{INTRODUÇÃO}

Em Quadros Geográficos; uma forma de ver, uma forma de pensar, o geógrafo carioca Paulo César da Costa Gomes (2017, p. 13) afirma que a Geografia pode ser considerada "uma forma de pensar [...], uma maneira, original e potente, de organizar o pensamento". Tal ideia possibilitou-nos conectar esse campo do saber com o modo de vida das pessoas e como essas inventam e manejam grafias para inscrever e registrar suas ações, seus pensamentos, seus desejos e seus medos acerca de tudo aquilo que as move nos espaços, mesmo aqueles intersticiais. O audiovisual teria se tornado, nesse primeiro quartel do século XXI, uma dessas formas de captura, registro e grafia, com a qual estamos a transformar os espaços, desde

$\begin{array}{llllll}\text { (C) ETD-Educação Temática Digital } & \text { Campinas, SP } & \text { v.23 } & \text { n.2 } & \text { p.335-353 } & \text { abr./jun.2021 }\end{array}$


aquele mais singular por nós habitado, até o espaço mais distante - visto e imaginado apenas por meio de imagens em movimento ou pelas imagens geográficas por excelência. Aproximação e distanciamento são dois substantivos tomados aqui como duas faces de uma mesma moeda. A depender de como experimentamos o espaço (próximo e/ou distante), será a intensidade produzida com ele e com todas as outras trajetórias humanas, inclusive daqueles e daquelas que já não estão mais entre nós, mas sobrevivem como arquivos de outrora.

Tributário de uma pesquisa mais ampla, envolvendo geógrafas-professoraspesquisadoras e geógrafos-professores-pesquisadores de universidades brasileiras e estrangeiras, este texto busca circunstanciar um território de pesquisa multifacetado: o resultado do encontro entre professores de geografia ${ }^{3}$ e o emprego que fazem de produções cinematográficas. Além disso, trouxemos outros três acontecimentos discursivos: um situado no contexto afetivo familiar, outro no âmbito de dois jornais internacionais, e, por fim, o Plano de Diretrizes e Metas para o Audiovisual (PDM), publicado em 2013 pela Agência Nacional do Cinema (ANCINE) ${ }^{4}$. Nosso propósito consiste, única e exclusivamente, na tentativa de escrever/pensar conexões entre esses quatro acontecimentos discursivos que, ao instituírem reais no tecido social urbano, possuem, no cinema e no audiovisual, a centralidade de uma grafia outra do presente, qual seja, a radicalização de um jeito de viver que não prescinda mais da feitura de "videozinhos" - em alusão às críticas de algumas pessoas concernentes à prática que caracterizaria o fazer cinematográfico e o oposto disso.

A problemática do audiovisual, ao operar como uma pedagogia cultural, evidencia como esse dispositivo vem sendo apropriado pelas pessoas em geral, embaralhando os limites de seus usos. Teríamos, assim, uma composição entre cinema e audiovisual, cujo saldo seria esse "algo" ou o "dente de macaco" do qual discorreu Manoel de Barros (2010) em "Sobre importâncias", e acerca do qual nos devotamos nesse texto. A hipótese de trabalho escrutinada é que o audiovisual se tornou um dispositivo que tem radicalizado o autogoverno e o governo dos outros como gesto educativo não mais circunscrito aos cineastas e profissionais vinculados ao audiovisual. Tal gesto estaria alastrado e imiscuído na sociedade como efeito de uma potente pedagogia cultural, localizada em torno da sociedade educativa ou da aprendizagem, cuja

\footnotetext{
${ }^{3}$ Ao longo desse texto, grafamos geografia com " $\mathrm{g}$ " minúsculo, pois entendemos que não exista uma geografia absoluta, transcendental, teleológica, mas, sim, uma multiplicidade de geografias à medida que se remonta as compreensões acerca das espacialidades, das temporalidades e das trajetórias humanas e inumanas (Massey, 2008).

${ }^{4}$ Autoridade regulatória do mercado de conteúdos audiovisuais brasileiro.
} 
[...] fortaleza está associada à disseminação e expansão da governamentalidade liberal (e neoliberal), essa forma econômica de governamento que pretende governar menos para governar mais, isto é, essa forma de governar cujo fundamento é a liberdade, o interesse, a agência e autorregulação dos indivíduos. Podemos dizer que a aprendizagem é hoje a forma do governamento pedagógico, 0 governamento não mais do cidadão, mas do "aprendiz permanente", do Homo discentis. Aprender ao longo da vida, aprender a aprender é a divisa do governamento contemporâneo. Estamos sendo compelidos a nos comportar como aprendizes permanentes, que moram em sociedades de aprendizagem ou cidades educativas. (NOGUERA-RAMÍREZ, 2011, p. 203).

Esse seria o saldo do encontro entre a educação e audiovisual: uma aprendizagem vitalícia e autogovernada, extrapolando as fronteiras disciplinares, agora dispostas em trânsito constante e sem contornos definidos. Assim, o sentido e o não-sentido do encontro entre educação e audiovisual adensa uma problemática atual: educar tornou-se prerrogativa da sociedade educativa. A despeito de o referido paradoxo (fazer sentido e não fazer sentido) ser insolúvel, especialmente no campo educacional, como pensar em processos educativos cuja primazia gravite mais em torno da ideia de composição entre o sentido e o não-sentido, e menos em dispor um em detrimento do outro? Ou seja, como construir um pensamento geográfico visual (não apartado da palavra, afinal, precisamos dela para produzir legibilidade às imagens), imbricado em suas espacialidades e temporalidades com o fito de tensionar o já sabido e o que pode ser conhecido no trabalho de escavação feito pelo/a professor/a no encontro entre audiovisual, cinema, educação e as múltiplas geografias oriundas do trabalho arqueológico visual? Buscaremos discutir tal pergunta ao longo desse texto, não de modo literal, claro está, mas partindo da linguagem audiovisual ao invés somente da linguagem cinematográfica, porque entendemos que a segunda integra a primeira. Assim, duas justificativas fazem-se necessárias. A primeira diz respeito ao motivo pelo qual lidamos com a linguagem audiovisual ao invés da cinematográfica. A noção de audiovisual é mais alargada e, por incluir a linguagem cinematográfica, tem se configurado como âncora de nosso modo de vida, especialmente após o advento do período técnico-científico e informacional. Dizendo de outro modo, tornamo-nos fazedores de audiovisuais e essa prática tornou-se, quiçá, fulcral para existirmos. A segunda justificativa concerne ao fato de que tanto o audiovisual quanto o cinema estão fora e, concomitantemente, dentro do escopo educacional. Ou seja, ambos não são feitos para serem necessariamente empregados em contextos educacionais, com exceção, por exemplo, dos curtas-metragens realizados pelo Instituto Nacional do Cinema Educativo, que existiu de 1938 (ano de sua criação) a 1968, ano de encerramento de suas atividades.

Com o propósito de apresentar a problemática sobre a qual nos devotamos, qual seja, a conexão entre cinema/audiovisual, o campo da educação escolar e uma pesquisa comum, abordaremos, no próximo item, quatro peças discursivas: a primeira intitula-se "o dia que o audiovisual invadiu um diálogo familiar e (des)norteou a conversação"; a segunda peça diz 
respeito a relatos de estudantes publicados no New York Times e no El País (Brasil); a terceira concerne ao Plano de Diretrizes e Metas para o Audiovisual (PDM) e a quarta peça diz respeito aos resultados do questionário de uma pesquisa comum chamada As Telas da Escola: cinema e professores de geografia, envolvendo todas as universidades que integram a Rede internacional de pesquisas "Imagens, geografias e educação". Na última parte do texto discutiremos as quatro peças à luz de uma análise micropolítica para, ao fim e ao cabo, tecer considerações acerca do encontro de territórios tão distantes e, simultaneamente, tão próximos, que são os campos da geografia, da educação e do cinema/audiovisual.

\section{QUATRO PEÇAS DISCURSIVAS}

\subsection{Peça um: O dia que o audiovisual invadiu um diálogo familiar e (des)norteou a conversação}

Recentemente, em um contexto familiar, estabelecemos um diálogo com uma criança, por meio de uma chamada telefônica, usando o smartphone como ferramenta de comunicação. Ela, com idade em torno de 10 anos, ao atender o telefonema, disse-nos, de modo peremptório, que preferia seguir a conversa utilizando um aplicativo de compartilhamento de mensagens de seu dispositivo, pois, assim, além de nos escutar, seria possível ver nossas imagens em movimento. Enquanto justificava seus motivos, listando as benesses de tal escolha, recusou-se, de pronto, a seguir conversando empregando somente o áudio. Ficamos extremamente irritadas, e, intrigadas!

A nosso ver, tendo em vista que queríamos somente conversar, bastava apenas falar e escutar a voz dela do outro lado. Entretanto, sua demanda foi bastante assertiva, de tal modo que listou rapidamente, como uma razão inegociável, sua necessidade por nos ver e igualmente ser vista, de modo que a conversa ficaria mais animada, mais vívida. Ademais, outro argumento pautado, já num misto de incompreensão e irritação, pois não compreendia nosso estranhamento, foi o fato de que poderia apoiar o telefone em uma mesa de sua casa enquanto conversava e, concomitantemente a isso, poderia nos ver, ser vista e, da mesma forma, mostrar as coisas que fazia em sua casa no decorrer de nossa conversação.

Vencidas, foi necessário acionar toda a maquinaria do dispositivo eletrônico para iniciar a chamada via audiovisual. Para ela, não fazia o menor sentido conversar pelo smartphone sem ver a nossa imagem e a dela em movimento. Ela fez uso até mesmo do recurso de espelhamento da imagem proporcionado pelo aplicativo, ou seja, ao mesmo tempo que nos via, contemplava a forja de sua própria imagem e encantava-se com isso. Entre uma geração e outra, delays entre a demanda de ouvir e ser ouvido e a necessidade de, coincidentemente, ouvir, compartilhar gestos e ver a outra pessoa, ao mesmo tempo que admirava a própria imagem. 


\subsection{Peça dois: Relatos de estudantes publicados em dois jornais}

No início do mês de maio do ano corrente, a adolescente norte-americana de 13 anos, Veronique Mintz, publicou uma matéria na seção de opinião do jornal New York Times. A estudante do eighth-grade student, que corresponde no Brasil ao oitavo ano do ensino fundamental, relatou sua experiência de aprendizado por meio das tecnologias utilizadas pelas escolas no contexto da pandemia da COVID-19. Mintz defendeu, de modo enfático, o ensino online realizado por meio de tecnologias de informação e comunicação, aliadas ao uso contínuo das imagens e sonoridades por meio de telas, ferramentas e materiais digitais ${ }^{5}$. Recuperemos alguns de seus argumentos.

Sou a favor do ensino a distância que o sistema escolar da cidade de New York instituiu quando a pandemia de coronavírus ocorreu [...]. O ensino a distância me dá mais controle sobre meus estudos [...]. Estou realmente gostando dos amigos do FaceTiming que trazem diferentes perspectivas e pontos fortes para o trabalho; desafiamos um ao outro e é uma experiência de aprendizado mais rica (MINTZ, 2020. Tradução nossa).

Pensando acerca dos argumentos de Mintz (2020), nos pareceu interessante apresentar, como contraponto, argumentos tecidos por três jovens estudantes brasileiras, em uma publicação do Jornal El País Brasil, de 12 de maio de 2020, intitulada Jovens têm choque de consciência sobre privilégios e injustiças do Brasil durante a pandemia (BETIM, 2020). Nessa matéria, um argumento transversal das estudantes, as quais conhecemos por meio do texto da reportagem e vídeos gravados por elas, trata das desigualdades sobrelevadas pelo contexto de pandemia. Dentre os elementos analisados pelas três jovens, que moram em diferentes locais do país, há uma problematização enfática sobre o formato de ensino online, tendo em vista as desigualdades que cada uma delas percebe em seu contexto escolar, social e pessoal.

As jovens reconhecem que a disponibilização de materiais de estudo nos meios virtuais durante a pandemia pode possibilitar que os estudos continuem de alguma maneira, mas é comum na fala das três a preocupação com quem não consegue acessar essas tecnologias e materiais. Dentre os motivos listados por elas estão as desigualdades econômicas e sociais; as incertezas e instabilidades materiais e emocionais ocasionadas por desdobramentos da pandemia nas vidas das pessoas; a falta de acesso à internet de grande parte da população; o movimento paradoxal das subjetividades, pois uma parte das pessoas exalta as possibilidades criativas e produtivas desse período de isolamento social e outra

\footnotetext{
${ }^{5}$ Não trouxemos o relato da referida estudante para advogar em prol do ensino a distância, mas com o intuito de apresentá-lo como superfície discursiva ou, dizendo de outra maneira, mais uma peça do puzzle do modo de vida na contemporaneidade.
} 
parte passa por um período muito difícil dadas as vulnerabilidades socioeconômicas agudizadas no período supramencionado.

\subsection{Peça três - Plano de diretrizes e metas para o audiovisual (PDM)}

O Plano de diretrizes e metas para o audiovisual: o Brasil de todos os olhares para todas as telas (ANCINE, 2013), diz respeito ao macroplanejamento estratégico do mercado audiovisual brasileiro. Foi formulado com o propósito de detalhar e parametrizar diretrizes e metas para a década de 2011 a 2020, articulando tais dados e informações na busca de produção de estratégias e consensos no setor audiovisual. $O$ documento está organizado em treze diretrizes. A primeira é denominada Diretriz Geral e as outras doze são nomeadas de acordo com sua numeração - de um a doze, seguidas de um subtítulo. Nem todos os temas trazidos pelas treze diretrizes do PDM são foco de nosso estudo, mas é importante mencionar que tomar contato com esse material viabilizou miradas mais amplas acerca de direcionamentos políticos do setor audiovisual brasileiro, os quais se cruzam com as correlações que empreendemos.

$\mathrm{Na}$ Diretriz Geral foram propostos dois vetores para pensar a atividade audiovisual no país, evidenciando um desejo de equilíbrio entre eles. O primeiro vetor diz respeito à dimensão da organização econômica do audiovisual, compreendendo a necessidade de considerar as dinâmicas das empresas, além da alocação de recursos públicos no setor. 0 segundo vetor focalizou a importância da existência de diversidade nas obras realizadas e exibidas no país, realçando perspectivas artísticas e de produção. De acordo com o texto do PDM, o desequilíbrio entre esses vetores poderia agravar vulnerabilidades políticas, institucionais, além de sufocar a produção de obras centradas na criatividade, diversidade e inovação de temáticas e formatos.

A ênfase excessiva no espectador distancia a obra audiovisual de sua peculiaridade, dissolve a diversidade e a autoria, domestica a criatividade e reduz a produção e a distribuição a um mero exercício mercantil. Pela outra ponta, o excesso de foco no criador e no produtor aliena a obra de seus públicos, enfraquece as empresas, hipertrofia a disputa pelos recursos públicos, retira apoio social ao setor e solapa a legitimidade das instituições e das políticas. O resultado do primeiro enfoque é um audiovisual sem viço e qualidade; do segundo são políticas e instituições sem permanência. (ANCINE, 2013, p. 81)

As outras diretrizes articularam transversalmente a busca de equilíbrio entre os dois vetores suprarreferidos. A última diretriz, em especial, a de número doze, intitulada Ampliar a participação do audiovisual nos assuntos educacionais, focalizou diretamente o desejo de aproximar a educação e o audiovisual, "tanto para a circulação das obras e o exercício crítico, quanto para o compartilhamento das técnicas de produção e da linguagem" (ANCINE, 2013, p. 97). Nessa diretriz lemos acerca da possibilidade dessa correlação entre os setores audiovisual e educacional viabilizar a ampliação de públicos e o compartilhamento de técnicas

$\begin{array}{llllll}\text { (C) ETD-Educação Temática Digital } & \text { Campinas, SP } & \text { v.23 } & \text { n.2 } & \text { p.335-353 } & \text { abr./jun.2021 }\end{array}$


de produção e da linguagem audiovisual. Essas formulações demonstraram o desejo de articulação entre o setor audiovisual e educacional no país. Ao adentrar o território educacional, o audiovisual usufruiria da ampla capilaridade já existente, pois "considerada apenas a rede pública de ensino básico, a estrutura de educação formal representa o serviço público com maior capilaridade no país, com imenso significado na vida das comunidades" (ANCINE, 2013, p. 97). Do lado das escolas, o documento considera como fator positivo a possibilidade de articulação entre comunidade, linguagem audiovisual e práticas pedagógicas. Uma outra sugestão do texto pondera acerca de parcerias com o Ministério da Educação, pois essas poderiam promover "a sustentabilidade do setor por meio de compras públicas de direitos sobre as obras, além de fortalecer o ambiente de difusão" (p. 97).

Vale mencionar que um provável desdobramento dos desejos de articulação expostos na diretriz 12 refere-se à promulgação da Lei no 13.006, de 26 de junho de 2014. Essa lei, resultado do Projeto de Lei 185/08, altera o artigo 26 da Lei no 9.394, de 20 de dezembro de 1996 (que estabelece a Lei de Diretrizes e Bases da Educação Nacional - LDBEN), acrescentando o parágrafo 80: "A exibição de filmes de produção nacional constituirá componente curricular complementar integrado à proposta pedagógica da escola, sendo a sua exibição obrigatória por, no mínimo, 2 (duas) horas mensais" (BRASIL, 2014). A partir dos debates realizados pela promulgação da referida lei, foi publicado o livro Cinema e educação: a lei 13.006 - Reflexões, perspectivas e propostas, constituído por 20 reflexões e propostas teórico-metodológicas "sistematizadas por 40 profissionais de diferentes grupos de pesquisas das universidades brasileiras, professores de educação básica, cineclubistas, que vêm trabalhando na interface do cinema e educação" (FRESQUET, 2015, p. 02).

\subsection{Peça quatro: Respostas do questionário As Telas da Escola (Polo SP)}

Lançamos mão, por fim, das respostas concernentes ao questionário "As telas da escola: cinema e professores de geografia" ${ }^{6}$. Esse questionário está vinculado a uma investigação acerca da regulamentação da Lei 13006/14 (BRASIL, 2014) que envolve todos os polos da Rede Internacional de Pesquisa Imagens, geografias e educação7 ${ }^{7}$ O questionário foi elaborado com perguntas abertas e fechadas e teve como principal objetivo relacionar cinema e práticas de professoras e professores de geografia em diversas localidades do país. As respostas que tomamos como material de análise nesse trabalho são aquelas vinculadas ao Polo São Paulo, e, ao Grupo de Pesquisas Interdisciplinares em Culturas Visuais (MIRAGEM), sediado na Escola de Artes, Ciências e Humanidades (EACH) da Universidade de

\footnotetext{
${ }^{6}$ O questionário-entrevista encontra-se anexo à Apresentação desse Dossiê.

${ }^{7}$ Polos da rede. Disponível em: https://www.geoimagens.net/polos-da-rede . Acesso em: 12 ago. 2020.
}

(C) ETD- Educação Temática Digital Campinas, SP $\quad$ v.23 $\quad$ n.2 $\quad$ p.335-353 abr./jun.2021 
São Paulo (USP) ${ }^{8}$. Buscamos mirar cruzamentos entre demandas amplas dos setores audiovisual e educacional, e movimentações cotidianas entre linguagens, tecnologias e práticas educativas para, assim, quiçá, vislumbrar, nessas respostas, linhas de vida traçadas pelas movimentações do desejo nos dias atuais.

\begin{abstract}
Todo este contexto acadêmico, político, institucional e cultural transformou a temática do cinema em algo bastante pulsante e muito atual e nos dá elementos para enfrentarmos nosso problema: a atualização do entendimento das perspectivas criadora e criativa do uso das linguagens no ensino de Geografia [...]. Estamos, sim, trabalhando com a ideia de cartografia amparada na filosofia da diferença, em que cartografar é acompanhar as linhas intensivas - molares, moleculares e de fuga - que compõem mapas, sendo estes mapas entendidos como aquilo que está entre dois corpos de qualquer natureza (DELEUZE; GUATTARI, 1995). Estas linhas são as linhas de vida, linhas abstratas que o desejo vai traçando". (OLIVEIRA JUNIOR; GIRARDI, 2020, p. 55).
\end{abstract}

Visando delinear correlações entre as demais peças discursivas que apresentamos nesse trabalho e linhas de vida oriundas desse questionário, destacamos, em um primeiro momento, três aspectos gerais das respostas vinculadas ao Polo São Paulo: a) dentre os respondentes, 90\% trabalham com a disciplina de geografia e, desses, 22,2\% ministram aulas concernente à disciplina de História; b) $50 \%$ dos respondentes têm entre 5 e 10 anos de docência, 30\% têm entre 11 e 20 anos, e 20\% têm entre 21 e 30 anos de docência; e c) acerca da preferência sobre o local de exibição na escola: $50 \%$ têm preferência por exibir os filmes na sala de vídeo e os outros $50 \%$ preferem a sala de aula como local de exibição. Dentre outros locais de exibição que figuraram no questionário, alguns professores escolheram a sala de informática e o pátio. Ao serem inquiridos e tendo como opção uma resposta dissertativa, $40 \%$ responderam que não há outro espaço para exibição e $30 \%$ responderam que uma possibilidade seria a sala de leitura.

Observando as respostas da pergunta "Quais filmes você usa para trabalhar conteúdos ou temas de geografia?", buscamos observar os filmes mencionados mais de uma vez pelos respondentes. A partir do conjunto de filmes mencionados, observamos quais deles são filmes brasileiros, quais são curtas ou longas, quais são documentários e quais temáticas são mais trabalhadas a partir deles (Quadro 1). De posse do recorte realizado, o total de filmes mencionados mais de uma vez pelos respondentes do Polo São Paulo é igual a dez. Destes, seis referem-se a produções nacionais; sete são longas-metragens; seis correspondem ao gênero fílmico denominado drama; há uma recorrência ampla da utilização desses materiais para debater sobre questões sociais, urbanas e regionais, dentre outras. Apesar do gênero fílmico mais recorrente ter sido o drama, é interessante notar a diversidade que aparece nas

\footnotetext{
${ }^{8}$ Miragem - Grupo de Pesquisas Interdisciplinares em Culturas Visuais (EACH-USP). Disponível em: http://miragemcveg.blogspot.com/. Acesso em 03 out. 2020.
}

(C) ETD-Educação Temática Digital Campinas, SP $\quad$ v.23 $\quad$ n.2 $\quad$ p.335-353 abr./jun.2021


respostas, por trazerem filmes de animação, comédia, ação, filmes históricos e documentários. Essa diversidade figura nas diferentes correlações realizadas com os temas trabalhados em sala de aula.

QUADRO 1. Filmes mencionados mais de uma vez pelos respondentes do Polo São Paulo

\begin{tabular}{|c|c|c|c|c|c|c|}
\hline Filmes mais citados & $\begin{array}{l}\text { num de vezes } \\
\text { mencionado }\end{array}$ & gênero & $\begin{array}{c}\text { duração } \\
\text { (minutos) }\end{array}$ & ano & $\begin{array}{c}\text { filme } \\
\text { brasileiro? }\end{array}$ & $\begin{array}{l}\text { temas mais } \\
\text { trabalhados }\end{array}$ \\
\hline Tempos Modernos & 4 & comédia & $89^{\prime}$ & 1936 & não & geografia econômica \\
\hline O Pianista & 3 & Drama & $150^{\prime}$ & 2002 & não & $\begin{array}{c}\text { geopolítica, geografia } \\
\text { histórica }\end{array}$ \\
\hline Ilha das flores & 3 & documentário & $15^{\prime}$ & 1989 & $\operatorname{sim}$ & $\begin{array}{l}\text { geografia urbana, } \\
\text { questões sociais }\end{array}$ \\
\hline Narradores de Javé & 2 & Drama & $100^{\prime}$ & 2003 & $\operatorname{sim}$ & $\begin{array}{c}\text { geografia regional, } \\
\text { questões sociais }\end{array}$ \\
\hline Hotel Ruanda & 2 & $\begin{array}{c}\text { Drama/Filme } \\
\text { histórico }\end{array}$ & $122^{\prime}$ & 2004 & não & geopolítica \\
\hline O auto da compadecida & 2 & comédia, drama & $104^{\prime}$ & 2000 & $\operatorname{sim}$ & geografia regional \\
\hline Diamante de Sangue & 2 & drama & $134^{\prime}$ & 2006 & não & questões sociais \\
\hline
\end{tabular}

Fonte: Elaborado pelas autoras a partir das respostas do questionário "As telas da escola: cinema e professores de geografia".

Acerca da duração dos filmes, dentre diversos longas-metragens, dois curtasmetragens foram mencionados mais de uma vez pelos(as) docentes, ensejando-nos a pensar acerca do potencial desse formato para a realização de atividades em sala de aula (WEBINAR, 2020). Esse potencial do curta-metragem em sala de aula está relacionado às respostas para a pergunta do questionário "Como você usa os filmes na escola?", pois aparecem várias indicações do uso de trechos de filmes nas aulas. Para essa pergunta, os respondentes poderiam selecionar quatro opções de respostas fechadas, em ordem de preferência. Eram elas: passa o filme inteiro; passa vários trechos de um mesmo filme; passa só um trecho que interessa; passa trechos de vários filmes. E, além dessas opções, havia espaço para uma resposta dissertativa aberta. Como resultado da primeira opção de uso, $80 \%$ indicaram passar o filme inteiro e $20 \%$ afirmaram passar vários trechos de um mesmo filme. Na segunda opção da ordem de preferência, $30 \%$ indicaram passar só um trecho que interessa; $30 \%$ indicaram utilizar vários trechos de um mesmo filme; $10 \%$ optaram por trechos de vários filmes; e os $30 \%$ restantes deixaram essa opção em branco. A terceira e a quarta opção foram pouco respondidas, mas nas respostas predominou a escolha por exibir trechos de filmes e não filmes inteiros. Apenas $20 \%$ dos/as docentes preencheram o campo das respostas dissertativas, indicando usos fora da sala de aula, em situações recreativas e em eventos da escola.

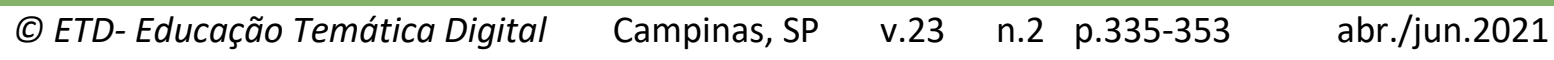


Outra observação trata do ano de lançamento dos filmes. Dentre os dez listados no Quadro 1, oito foram lançados depois do ano 2000, permitindo afirmar que houve uma busca por filmes conectados a questões pulsantes em nossos dias. Tal tópico relaciona-se a uma provável demanda de professores pelo acesso a conteúdos audiovisuais que possam ser articulados a suas discussões em aula, visando debater temas políticos, sociais, urbanos, locais e globais da atualidade. É interessante notar que os outros dois filmes, Tempos Modernos (1936) e Ilha das Flores (1989), apesar de terem sido lançados anteriormente, possuem temáticas que seguem atuais, ainda propiciando discussões bastante relevantes para problemáticas do presente.

Além desse conjunto de filmes organizado no Quadro 1, selecionamos mais algumas respostas do conjunto de professores(as) de geografia que respondeu ao questionário do Polo São Paulo, pois conectam-se às peças discursivas desse trabalho, como linhas de fuga, dizendo "algo" acerca de nossos modos de vida na atualidade. Esse "algo" conecta-se a movimentações no espaço entre subjetividades, audiovisual e educação na contemporaneidade (GONÇALVES, 2020).

Em resposta à pergunta: "Quais filmes você usa para trabalhar quais conteúdos ou temas de geografia?", chamou nossa atenção o comentário de dois docentes ao dizerem, nas respostas abertas, utilizar, em sala de aula, "séries da BBC" e "documentários do Youtube". Dentre as respostas a seguir, as duas primeiras referem-se à inquirição: "Escreva uma frase sobre as relações entre escola e cinema"; e, a terceira, à pergunta "Você seleciona filmes que exibe na escola de outra maneira?".

\footnotetext{
[Resposta um]: “Trazer conteúdos transversais enriquece a aula, e o audiovisual é uma ferramenta indispensável para o professor, por exemplo a adaptação do Livro de Machado de Assis, Pai Contra Mãe, que no cinema virou "Quanto vale ou é por quilo".

[Resposta dois]: "Um recurso audiovisual interessante".

[Resposta três]: "Filmes com conteúdos pertinentes ao material pedagógico utilizado na escola ou com trabalho interdisciplinares, ou algum episódio de seriados de televisão como a série Cidade dos Homens onde narra a saga dos personagens Acerola e Laranjinha em especial os episódios "Coroa do Imperador e Correio".
}

Essas respostas nos lançaram para um território de análise mais amplo. Isso se deu, pois, a despeito de o objetivo inicial do questionário ter sido circunscrito em perceber correlações entre cinema e práticas docentes de professores(as) de geografia, notamos já fazer parte de nossas práticas diárias certo esboroamento de fronteiras entre audiovisual e cinema. Importa dizer que compreendemos o audiovisual como uma coligação entre imagens e sonoridades, de tal modo que o cinema pode ser considerado como parte dos fazeres audiovisuais (LONGHI, 2014). 
Ressaltamos isso, porque corriqueiramente temos lidado com imagens e sons das mais diversas maneiras. Utilizamos o audiovisual para realizar registros de momentos ímpares, para grafar nossas trajetórias e/ou solucionar rapidamente problemas da vida em suas diversas camadas, amplitudes e minúcias. Por isso, nos pareceu interessante observar que parte dos respondentes trouxe esses elementos em suas respostas. Dessa maneira, traçaremos, no próximo item, algumas relações entre as respostas desse questionário e movimentações mais amplas a permear o tecido social atual, concatenadas nesse trabalho por meio das três peças anteriores.

\section{PROCEDIMENTO METODOLÓGICO}

Ao partirmos dessas quatro peças que compõem parte da superfície discursiva dos modos de vida do presente, nosso objetivo com esse texto consiste em realizar uma análise micropolítica, inspirada no modo de traçar cartografias conforme apresentado por Félix Guattari e Suely Rolnik, no livro Micropolítica: Cartografias do Desejo. (GUATTARI; ROLNIK, 2013). Uma análise micropolítica compreende "uma analítica das formações do desejo no campo social" (GUATTARI; ROLNIK, 2013, p. 149). Trata-se de observar as movimentações do desejo, os quereres em diferentes escalas. Para esses autores, o molar localiza-se nos grandes desejos, no "nível da política de constituição das grandes identidades" (GUATTARI; ROLNIK, 2013, p 150). O molecular está nos microprocessos, nas microrrelações, na ordem "dos fluxos, dos devires, das transições de fases, das intensidades" ( $p$ 386).

Podemos pensar a análise micropolítica como um espaço entre (GONÇALVES, 2020), um espaço de pensamento, no qual "múltiplos fatores podem ser conjugados e articulados por meio de cruzamentos de linhas de forças de diferentes temporalidades, velocidades, densidades, ritmos e escalas" (p. 99). Um território de correlações entre o nível molar, que abarca problemáticas mais abrangentes da sociedade, e o nível molecular, dos encontros, dos afetos. Não se trata de uma oposição nem de uma análise binária entre dois polos distintos. Também não diz respeito a um modelo fixo, "o problema de uma analítica micropolítica é justamente o de nunca usar um só modo de referência" (GUATTARI; ROLNIK, 2013, p. 154).

A análise micropolítica se situaria exatamente no cruzamento entre esses diferentes modos de apreensão de uma problemática. É claro que os modos não são apenas dois: sempre haverá uma multiplicidade, pois não existe uma subjetividade de um lado e, do outro, a realidade social material. Sempre haverá " $n$ " processos de subjetivação que flutuam constantemente segundo os dados, segundo a composição dos agenciamentos, segundo os momentos que vão e vêm. E é nesses agenciamentos que convém apreciar o que são as articulações entre os diferentes níveis de subjetivação e os diferentes níveis de relação de forças molares. (GUATTARI; ROLNIK, 2013, p. 155). 
Nossa análise micropolítica dialoga com Guattari e Rolnik (2013, p. 149), pois "diz respeito ao modo como o nível das diferenças sociais mais amplas (que chamei de 'molar') se cruza com aquele que chamei de 'molecular'. Entre esses dois níveis, (sic) não há uma oposição distintiva, que dependa de um princípio lógico de contradição". Para realizar essa análise faz-se necessário uma mudança de lógica, afinal, não concerne a uma análise maniqueísta e tampouco correlaciona-se às ideias de micro e macro, mesmo porque, como alertam os autores, "essa oposição entre molar e molecular pode ser uma armadilha" (p. 150). Embora os níveis molares e moleculares sejam diferentes, "o molecular, como processo, pode nascer no macro. O molar pode se instaurar no micro" (p. 150).

Relacionamos, portanto, as diretrizes e metas do PDM (ANCINE, 2013) com as outras três peças discursivas. Buscamos identificar como as movimentações do desejo do setor audiovisual brasileiro apareceram expressas no PDM, primeira peça apresentada, para assim tecermos relações entre questões identificadas no PDM e aspectos específicos de nossas vidas nos dias atuais. Utilizamos a estratégia de compor esse cenário de análise por meio de peças, pois, cada uma a seu modo, delineia assuntos, práticas e fluxos relacionados com nossos modos de viver. Dessa maneira, elaboramos, de modo pormenorizado, pontos de cruzamento entre as amplitudes acontecimentais e aquelas ocorrências costumeiras da vida em nossos dias. Visamos, com isso, pensar conexões entre algumas das macroestratégias do desejo do setor audiovisual brasileiro expressas no PDM e detalhamentos de nossas cotidianidades.

\section{DISCUSSÃO DAS QUATRO PEÇAS DISCURSIVAS}

As quatro peças apresentadas evidenciam micropolíticas entre o setor audiovisual na interface com o campo educacional brasileiro. As peças 1 e 2 tratam-se de acontecimentos inscritos na microescala do cotidiano das pessoas, ao passo que as peças 3 e 4 operam com elementos da macroescala de decisões circunscritas às políticas públicas, tentando aproximar audiovisual e educação. Essa divisão entre micro e macro escala é apenas com fins didáticos, pois ambas estão imbricadas uma na outra, demandando uma análise micropolítica, que é o cruzamento entre uma e outra (GUATTARI, ROLNIK, 2013). Ou seja, nossas vidas são atravessadas pelos efeitos das decisões tomadas no âmbito das políticas do setor audiovisual brasileiro, concordemos ou não com tais decisões.

Para discutir as quatro peças apresentadas e perspectivadas desde uma análise micropolítica, lancemos mão, agora, daquilo que lemos no website da Ancine acerca do PDM: "o Plano não constitui uma pauta de obrigações e compromissos para os agentes públicos ou privados, no sentido jurídico mais estrito. Trata-se, antes, de um mapa do caminho [...]" (ANCINE, negrito nosso). O referido mapa vislumbrou tendências e aproximações setoriais estratégicas, objetivando criar caminhos a serem percorridos pelo setor audiovisual no

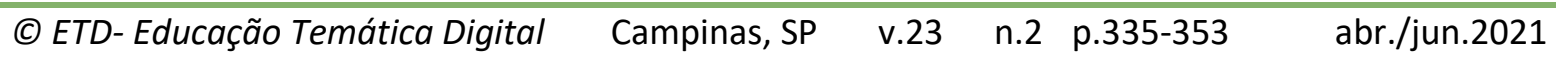


período de 2011 a 2020 no Brasil. Uma dessas articulações setoriais foi expressa na décima segunda diretriz do plano, mencionada anteriormente, objetivando prospectar a ampliação da participação do audiovisual nos assuntos educacionais. Recuperamos o trecho, na íntegra:

A maior aproximação entre o audiovisual brasileiro e a rede de ensino é alternativa, tanto para a circulação das obras e o exercício crítico, quanto para o compartilhamento das técnicas de produção e da linguagem. Os ganhos podem ser recíprocos. De um lado, considerada apenas a rede pública de ensino básico, a estrutura de educação formal representa o serviço público com maior capilaridade no país, com imenso significado na vida das comunidades.

[...] De outra parte, hoje, as obras audiovisuais são elementos indispensáveis à educação, independentemente de sua utilização formal no processo de ensino e aprendizagem. Parte cada vez mais significativa das referências cognitivas $e$ normativas, especialmente dos mais jovens, é constituída a partir de produtos audiovisuais. (ANCINE, 2013, p. 97, itálico nosso).

Essas perspectivas de união do audiovisual com a educação coligam-se à promulgação da Lei 13.006/14 (BRASIL, 2014), conectando os anseios enunciados no PDM com as salas de aula brasileiras. Tal movimentação, ao mesmo tempo que conecta à linguagem cinematográfica o potencial de transversalizar os conteúdos das disciplinas escolares, expõe problemáticas que demandam ponderações. Como exemplo convém mencionar a complexa questão relativa ao acesso desses conteúdos pelos docentes. Apesar de o discurso pautar-se na democratização e ampliação do acesso promovido pelo PDM (ANCINE, 2013), muitos conteúdos são difíceis de ser acessados por professores e professoras.

A utilização estratégica do digital como tecnologia capaz de aumentar a diversidade de conteúdos e possibilitar novas janelas de exibição traz, simultaneamente, a ampliação das travas de acesso aos mesmos conteúdos que os produtores buscam disseminar. Ponderamos sobre isso justamente porque, ao dissolver fronteiras e ampliar as janelas de exibição, grande parte dos conteúdos está pulverizada entre os diversos canais de televisão por assinatura e/ou on demand. Assim, do mesmo modo que o digital propõe capilarizar os conteúdos, isso pode ter um efeito paralisante, tendo em vista que os diferentes regulamentos das operadoras podem dificultar as possibilidades de acesso a determinados produtos audiovisuais.

Se somarmos a isso a problemática da falta de infraestrutura de banda larga no país, bem como as desigualdades de acesso a equipamentos informáticos e conexão de internet, conforme mencionadas pelas três estudantes na peça dois, antevemos correlações de nossa discussão com efeitos do fenômeno conhecido como abismo digital, ou seja, uma profunda contradição entre a inclusão e a exclusão digital. "Segundo a União Internacional de Telecomunicações, UIT, 3,6 bilhões de pessoas continuam excluídas da comunicação online" (ONU, 2019). Esse abismo não se resume apenas à escassez de máquinas técnicas, mas sobretudo, no entravamento das possibilidades de criar modos de viver coligados aos

\begin{tabular}{|c|c|}
\hline (C) ETD-Educacão Temática Diqital & Campi \\
\hline
\end{tabular}


processos de digitalização em voga nos dias que correm. Isso ocorre em diversas áreas da vida, desde o registro e o manejo pessoal de grafias fotográficas, textuais, cartográficas e audiovisuais, até à aquisição de habilidades, visando inserção profissional no mercado de trabalho. "A exclusão digital não é ficar sem computador ou telefone celular. É continuarmos incapazes de pensar, de criar e de organizar novas formas" (SCHWARTZ, 2000, apud FANTIN; GIRARDELLO, 2009, p. 71).

Ao mesmo tempo que o digital logra efetivar muitas das metas expostas no PDM (ANCINE, 2013), ao ampliar possibilidades de acesso via novos modelos de negócio, janelas de exibição e financiamentos, essa mesma tecnologia pode restringir o acesso que as diretrizes e metas do PDM tanto dizem almejar. Ademais, se há o desejo de aproximar o setor audiovisual e a educação básica brasileira para que o efeito de tal conexão ressoe nas salas de aula do país, urge que ocorram articulações intersetoriais efetivas. Dizemos isso por pensar que, apesar da demanda de professores e professoras por materiais audiovisuais que dialoguem com temas atuais, mencionada na peça quatro, a busca pelo acesso pode tornarse uma tarefa árdua e até inexequível. Dentre os motivos, podemos mencionar a crescente desvalorização da profissão docente no país, de modo que se não existir a possibilidade de acesso gratuito aos conteúdos, já pode estar estabelecida, de largada, uma considerável barreira socioeconômica de aproximação entre audiovisual e educação no Brasil. Além do que a multiplicidade de janelas demandaria ampla articulação no que diz respeito à formação docente para utilizar essas linguagens, do contrário, novamente pode ocorrer que as benesses prometidas por tal tecnologia transformem-se em empecilhos, inviabilizando possibilidades de diálogos profícuos entre audiovisual e educação.

Uma questão fulcral, ao exibirmos filmes nas escolas, diz respeito às condições dessa exibição. Os filmes costumam ser realizados visando condições ideais de exibição, por exemplo, salas de cinema, mas quando esses mesmos filmes são deslocados para as ambiências escolares, as condições de exibição tendem a ser bastante diferentes. A depender da infraestrutura da escola, a qualidade da projeção pode ser comprometida de muitas maneiras, pois atravessamentos de toda ordem fazem parte do cotidiano escolar. Além disso, a exibição dessas peças audiovisuais ocorre em diversas outras janelas, incluindo as telas dos smartphones que empunhamos em nosso dia a dia.

Isso se conecta com algo candente nos dias que correm, a saber, um movimento de desterritorialização dos modos de assistir filmes/audiovisuais. Os processos de digitalização baralham essas fronteiras, tendo em vista que basta ter o arquivo salvo em seu gadget e/ou ter acesso a um sinal wi-fi ou, ainda, a aplicativos de reprodução de mídias, para assistir filmes e outras peças audiovisuais. Do mesmo modo está em curso outro movimento de desterritorialização que dialoga com o parágrafo anterior. Vivemos um esboroamento das fronteiras nos modos de fazer audiovisual; somos todos fazedores de audiovisual, ou

$\begin{array}{llllll}\text { (C) ETD-Educação Temática Digital } & \text { Campinas, SP } & \text { v.23 } & \text { n.2 } & \text { p.335-353 } & \text { abr./jun.2021 }\end{array}$


"videozinhos", nos tempos que vivemos. Utilizamos imagens e sonoridades para levar a cabo diversas tarefas rotineiras, desde o registro de momentos especiais até cotidianidades, tais como efetuar pagamentos, contratações e comunicarmo-nos das mais variadas maneiras. Podemos registrar e editar peças audiovisuais via gadgets pessoais, utilizando ou não de aplicativos conectados à internet, havendo aqueles com funções específicas voltadas para gravação e edição, entretanto essas funcionalidades estão passando a fazer parte de outros aplicativos. Um exemplo é o Google Meet, amplamente utilizado por professores e professoras no período da pandemia de COVID-19, aplicativo que, a princípio, realizaria somente videochamadas, mas também tem sido utilizado para gravar vídeos em take (tomada) único.

Além desses aplicativos mencionados há outros que, cada vez mais, têm sido mobilizados, visando a realização de vídeos para exibição posterior nas redes sociais. Um outro uso pode ser, simplesmente, compartilhar imagens e sons entre as pessoas, conforme descrevemos na peça 1, pois, naquela interação, a insistência da criança em falar conosco por meio do recurso audiovisual não previa a gravação daquele momento, mas, tão somente, a necessidade de, sincronicamente, interagir, compartilhar, ver e ser vista.

\section{DUAS ADVERTÊNCIAS OU DAS CONSIDERAÇÕES FINAIS}

Há uma década trabalhando com audiovisual na formação de professores de uma universidade pública brasileira, notamos que os estudantes não hesitam mais em captar imagens em movimento, aliás, quando esse tipo de atividade/exercício é solicitado, trata-se do preferido entre eles. É fato que, grosso modo, os estudantes gostam muito de fazer os tais "videozinhos". Assim, a fronteira entre cinema e audiovisual parece estar cada vez mais esboroada à medida que pessoas comuns tornaram-se adictas da feitura de vídeos, sejam eles $\operatorname{caseiros}^{9}$ ou não.

Assim, a primeira advertência é que as quatro peças discursivas suprarreferidas foram aqui apresentadas mais com o intuito de entabular uma problemática em jogo e menos com a finalidade de instaurar certa polêmica acerca do que seja ou não cinema, audiovisual, ou ainda, defender a sanha a qualquer custo da educação a distância. Os argumentos demonstrados aqui foram dois.

\footnotetext{
9 Convém mencionar que, em um dos longas-metragens do cineasta João Moreira Salles, "No intenso agora" (2017), ele empregou, na sua montagem e edição, audiovisuais caseiros feitos por sua mãe quando visitou a China, além de outros registros caseiros/amadores realizados por pessoas em outros países abordados no filme mencionado.
} 
O primeiro é de que, nos dias atuais, tem-se um modo de vida alicerçado na sociedade educativa, cujos efeitos intensificaram os agenciamentos entre corpo e espaço via dispositivos eletrônicos. Ao invés da supressão do espaço na desterritorialização das ambiências que, de fato, tem ocorrido, sobretudo em decorrência da pandemia de COVID-19, o espaço transformou-se em ambiência medular para a feitura de "videozinhos", (des)norteando o uso que é feito do cinema em contexto escolar. O emprego do verbo (des)nortear concerne a um paradoxo, pois o audiovisual, ao invadir as aulas de geografia, não está sendo disposto em detrimento do cinema, mas, compondo com ele um jeito outro de ensinar e de aprender, que não é melhor e nem pior do que os modos analógicos. Esse jeito outro diz respeito a uma composição de linguagens, suportes e condições técnicas e tecnológicas que transformaram o espaço-tempo da "antiga" sala de aula em uma ambiência, ao mesmo tempo online e presencial, ao mesmo tempo territorializada, desterritorializada, e, reterritorializada. Teríamos aqui a forja de uma metalinguagem geográfica, pois o espaço concreto segue sendo condição sine qua non para que a vida aconteça em suas diversas frentes e enfrentamentos, do contrário não necessitaríamos de cabos de fibra óptica para fazer com que nossas conexões banda larga ou $5 G$ funcionassem. É importante lembrar que sem um bom cabo de internet instalado no cômodo correto da casa ou do apartamento (condição para que o sinal seja distribuído de modo eficiente e com a quantidade necessária de megabits, via cabo ou via wi-fi), as duas ambiências da atual sala de aula de geografia, a online e a presencial (afinal, estamos cada vez mais presos em nossas casas, apartamentos etc.) não aconteceriam. Vale ressaltar, em lugares do planeta desassistidos, essas salas de aula paradoxalmente constituídas, entre o online e o presencial, inexistem.

O segundo argumento, decorrente do anterior, é que nosso cotidiano tem sido cada vez mais atravessado por vídeos realizados pelos mais diferentes motivos, mas, sobretudo, por serem compartilhados em redes sociais e aplicativos de mensagens. Não basta mais filmar ou até camerar (DELIGNY, 1977), mas, acima de tudo, compartilhar, ver e ser visto, e até audiovisualizar - para usar o verbo-neologismo, extraído da dissertação de mestrado intitulada: Arquivo-vida na contemporaneidade: composições de modos de viver nas fronteiras entre audiovisual, arquivos pessoais e educação (GONÇALVES, 2020).

A segunda advertência é que o audiovisual como gesto educativo tem sido deslocado para os espaços formais de educação, mas não somente; temos por hábito fazer vídeos e fazêlos circular - espécie de um modus vivendi de nossa cotidianidade. Isso nos leva a pensar sobre a forja de certa ambiência educativa na cultura ocidental via audiovisual, potencializada pela invenção do cinema. Dentre os vários usos que têm sido feitos da produção cinematográfica nas escolas e nas instituições de ensino superior, especialmente nas licenciaturas, o audiovisual situa-se no limiar de um paradoxo: o sentido e o não-sentido no encontro entre Educação e Audiovisual. O sentido costuma ser entabulado, na esteira das pedagogias

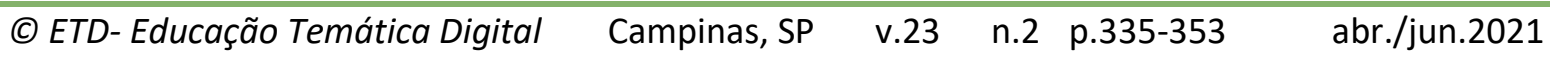


construtivistas, à axiomática de que tudo precisa fazer sentido quando se alude aos processos de ensino e aprendizagem, seja nas instituições formais de educação, seja nas não formais. 0 não-sentido, por sua vez, seria o oposto disso, acontecimentos rotineiros que atravessam e modificam a dinâmica tanto do tecido social, quanto das instituições escolares formais ou informais sem, na maioria das vezes, nos apercebermos disso. Outrossim, no contexto da sociedade educativa, a fronteira entre espaços formais e não-formais de educação dissolveuse, emergindo na ideia do conceito de aprendizagem - conceito pedagógico inédito que será "preponderante do século XX e, segundo parece, dos primórdios do século XXI" (NOGUERARAMÍREZ, 2011, p. 230).

Cremos que o audiovisual diz respeito a uma força disruptiva na maneira de operar como gesto educativo, subjetivando crianças, jovens, adolescentes e, de modo geral, as pessoas. Obviamente não há como ter garantias concernentes aos usos que os diferentes grupos sociais fizeram e estão a fazer dos audiovisuais. Trata-se de uma problemática cujas tentativas de explicar não são simples e tampouco dualistas. Por esse motivo optamos, como estratégia procedimental, pela realização de uma análise micropolítica (GUATTARI; ROLNIK, 2013).

\section{REFERÊNCIAS}

ANCINE. Plano de diretrizes e metas para o audiovisual: o Brasil de todos os olhares para todas as telas. 1.ed. jul. 2013. Rio de Janeiro: Agência Nacional do Cinema, 2013. Disponível em: https://www.ancine.gov.br/sites/default/files/PDM\%202013.pdf . Acesso em: 10 mai. 2020.

ANCINE. Notas sobre o Plano de Diretrizes e Metas para o Audiovisual 2011-2020. Disponível em: https://www.ancine.gov.br/pt-br/plano-de-diretrizes-e-metas . Acesso em: 10 mai. 2020.

BARROS, Manoel. Sobre importâncias. In: Memórias inventadas: as infâncias de Manoel de Barros. São Paulo: Planeta do Brasil, 2010. p. 109.

BETIM, Felipe. Jovens têm choque de consciência sobre privilégios e injustiças do Brasil durante a pandemia. Sociedade. El País, 12 mai. 2020. Disponível em: https://brasil.elpais.com/sociedade/2020-05-12/jovens-tem-choque-de-consciencia-sobreprivilegios-e-injusticas-do-brasil-durante-a-pandemia.html . Acesso em: 12 set. 2020.

BRASIL. Lei 13.006/2014, de 26 de junho de 2014. Presidência da República. Disponível em: http://www.planalto.gov.br/ccivil 03/ ato2011-2014/2014/lei//13006.htm . Acesso em: 28 mai. 2018.

DELIGNY, Fernand. Camérer: Texte Fernand Deligny, 1977. Trafic, $n^{\circ} 53$, printemps 2005, p. 54-59. Disponível em: http://derives.tv/Camerer/ . Acesso em: 07 mai. 2019. 
FANTIN, Monica; GIRARDELLO, Gilka Elvira Ponzi. Diante do abismo digital: mídia-educação e mediações culturais. Perspectiva, Florianópolis, v. 27, n. 1, p. 69-96, abr. 2010. Disponível em: https://periodicos.ufsc.br/index.php/perspectiva/article/view/2175795X.2009v27n1p69/12291 . Acesso em: 12 jan. 2020.

FRESQUET, Adriana. (2015). Cinema e educação: a lei 13.006 - Reflexões, perspectivas e propostas. Belo Horizonte, MG: Universo Produção.

GOMES, Paulo César da Costa. Quadros geográficos: uma forma de ver, uma forma de pensar. Rio de Janeiro: Bertrand Brasil, 2017.

GONÇALVES, Ingrid Rodrigues. Arquivo-vida na contemporaneidade: composições de modos de viver nas fronteiras entre audiovisual, arquivos pessoais e educação. 2020. 215 f. Dissertação (Mestrado em Educação) - Faculdade de Educação, Universidade de São Paulo, São Paulo, 2020.

GUATTARI, Félix; ROLNIK, Suely. Micropolítica - Cartografias do Desejo. 12.ed. Petrópolis, RJ: Vozes, 2013.

LONGHI, Raquel Ritter. O audiovisual como gênero expressivo e sua reconfiguração no jornalismo online. Estudos em Comunicação (16):69-88. 2014. Disponível em: http://ec.ubi.pt/ec/16/pdf/EC16-2014Jun04.pdf . Acesso em 22 set. 2019.

MASSEY, Doreen. Pelo espaço: uma nova política da espacialidade. Tradução de Hilda Pareto Maciel e Rogério Haesbaert. Rio de Janeiro: Betrand Brasil, 2008.

MINTZ, Veronique. Why I'm Learning more with distance learning than i do in school. Opinion. The New York Times. 05 mai. 2020. Disponível em: https://www.nytimes.com/2020/05/05/opinion/coronavirus-pandemic-distancelearning.html . Acesso em: 21 jun. 2020.

NOGUERA-RAMÍREZ, Carlos Ernesto. Pedagogia e governamentalidade ou Da Modernidade como uma sociedade educativa. Belo Horizonte, MG: Autêntica, 2011.

OLIVEIRA JUNIOR, Wenceslao Machado; GIRARDI, Gisele. O cinema como diferença na linguagem do ensino de geografia: uma cartografia provisória. Revista Brasileira de Educação em Geografia, Campinas, v. 10, n. 19, p. 45-66, jan./jun., 2020

ONU News. Estudo da ONU revela que mundo tem abismo digital de gênero. 6 nov. 2019. Disponível em: https://news.un.org/pt/story/2019/11/1693711 . Acesso em: 12 jan. 2020.

WEBINAR - Curtas-metragens na sala de aula | Curta Kinoforum. Youtube. Museu da Imagem e do Som de São Paulo - MIS. 2020. Disponível em: https://www.youtube.com/watch?v=BXYHAee1XOk . Acesso em: 06 set. 2020.

Revisão gramatical realizada por: Delvanir Lopes

E-mail: lopesdelvanir@bol.com.br 